\title{
A CASE OF EXFOLIATIVE DERMATITIS OF THE NEWBORN (RITTER'S DISEASE)
}

\author{
RECOVERY FOLLOWING TREATMENT WITH SULPHAPYRIDINE
}

BY

\author{
DOYNE BELL, D.M.,
}

Physician in Charge of the Children's Department, Queen Mary's Hospital for the East End,

AND

A. W. WOODS, B.M.,

House Physician to the Children's Department.

Acute exfoliative dermatitis of the newborn is a clinical rarity. In the paediatric and dermatological literature individual cases are reported, and from time to time small groups of three or four unconnected cases are collected.

Leiner (1930), over a period of twenty years, was able to observe only twenty cases of which eighteen were fatal. Yet, when Ritter von Rittershain (1878) first described the disease he based his observations on no fewer than 279 cases. These facts introduce a doubt as to whether or not Ritter's original series was a true clinical entity ; that there was some contemporary confusion on this point is emphasized by the controversy as to the nature of this condition which arose between Behrend (1879) and Ritter. Ritter, writing in 1880, was at pains to emphasize his original description of the condition and protested with acerbity against Behrend's confusion of the true acute exfoliative dermatitis of the new-born with pemphigus neonatorum.

And, indeed, Ritter's original description of the condition, the widespread loosening of the epidermis from the corium, without the preliminary formation of definite blebs or bullae, the rapid extension of the process of epidermolysis in the course of a few hours, and the exposed areas of dry, red corium, free from exudate, but surrounded by shreds of loosened epidermis-leaves a very definite picture which cannot be mistaken on the rare occasions when it is now seen. Yet, from a study of the literature of this subject it appears that there is still among modern writers some confusion of Ritter's disease with pemphigus and similar lesions of the newborn, though this confusion has largely been confined to discussions of the possible common etiology and pathogenesis of these clinically different conditions.

\section{Case report}

On November 6, 1941, a nineteen days old male infant was brought to hospital on account of a skin infection of the face. On November 1 he had been discharged with his mother from a maternity hospital, where the progress 
following a normal delivery had been uneventful except for a slight puffiness of his eyes on the last two days. On November 3 the eyes had become more swollen. There was a slight mucopurulent discharge, and the skin of the face was dry and scaling. On the day before admission, according to the mother"s account, a moist patch spread over the face and, on the day of admission, the face, parts of the chest, the buttocks and groins were involved. On undressing the baby in front of the mother, a raw patch about two inches across was revealed on the abdomen, and the mother uttered an involuntary exclamation of surprise, as this lesion had been much smaller when she had dressed the baby an hour or two earlier.

On admission to the ward the condition was as follows : temperature $100^{\circ} \mathrm{F}$., pulse 120 , respiration rate 40 . There were moist, raw patches over the scalp and cheeks and round the eyes, the lids of which were puffy, and from which a serous discharge was exuding. There were raw red areas, bordered by shreds of peeled epidermis on the neck, the front of the chest and abdomen, the groins, buttocks and parts of the back. Aczording to the mother, this condition had developed in the past six hours. There were no other abnormal physical signs.

Treatment. The baby was placed in a cot naked under an electric cradle, lying on cotton wool, with its legs and arms 'spread-eagled ' to prevent rubbing of the lesions. 2 per cent. aqueous solution of gentian violet was painted over the whole body once daily. M and B 693, 0.25 gm., was given four-hourly, the first dose intramuscularly and subsequent doses by mouth up to a total of $3 \cdot 5 \mathrm{gm}$.

Twenty-four hours after the initiation of treatment the areas of desquamation had spread slightly over the chest, back, buttocks and in the groins, but after forty-eight hours all spread had ceased. Repeated swabs taken from areas of exposed corium after the application of gentian violet gave a pure culture of staphylococci which haemolysed human red cells.

On the third day the temperature had fallen to normal (see chart) and $\mathbf{M}$ and B 693 was discontinued: but during the next two days the temperature swung up to $102^{\circ}$ and $103^{\circ}$, and in view of the bacteriological findings $M$ and $B 760,0 \cdot 125$ $\mathrm{gm}$., four-hourly, was given for seventy-two hours. The temperature, however, continued to swing to $103^{\circ}$ and $104^{2} \mathrm{~F}$. and a considerable degree of hyperpnoea developed. There were no signs of chest complications and no evidence of

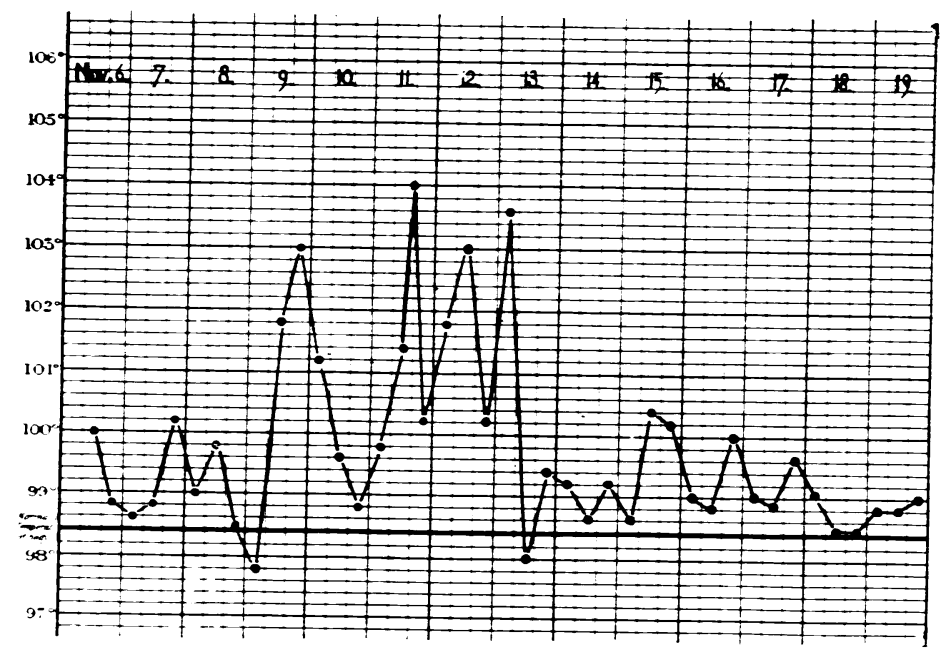

Temperature char:. For description see text. 
spread of the skin infection. It was concluded, therefore, that the pyrexia and the hyperpnoea were due to heat-stroke, owing to the application of gentian violet interfering with the normal heat-loss through the skin. The $M$ and B 760 was therefore discontinued and a larger, more airy electric cradle was used in which lower air-temperatures could be maintained. The child's temperature then fell and, apart from a rise to $100^{\circ} \mathrm{F}$. forty-eight hours later, remained between $98^{\circ}$ and $99^{\circ} \mathrm{F}$. for the rest of the baby's stay in hospital. The gentian violet coagulum was allowed to peel off little by little during the next ten days, revealing as it did so perfectly healthy skin. The skin of the neck was the last to heal entirely as it was impossible to prevent its being chafed by the movements of the baby's head.

Fortunately the feeding gave rise to no anxiety as the baby had a good appetite throughout and did not vomit. Expressed breast-milk was obtained from the mother, even when for a few days in the second week she had a superficial breast abscess. It is to be regretted that no culture was made of the pus from the abscess. The feeds were gradually increased from $3 \mathrm{oz}$. every three hours to $4 \frac{1}{2}$ oz. every four hours on discharge.

The weight of the baby at birth was $7 \mathrm{lb}$. $1 \mathrm{oz}$. and on admission $7 \mathrm{lb} .4 \mathrm{oz}$.; it then fell $12 \mathrm{oz}$. in the first nine days of the illness, but after that rose steadily, being $7 \mathrm{lb} .12 \frac{1}{2} \mathrm{oz}$. on discharge after one month in hospital.

\section{Comment}

The diagnosis of this case rests on the striking similarity of its appearance with those cases originally described by Ritter and with the few cases recorded subsequently. It is to be noted that there were no vesicles or bullae at the onset of the disease. The patches of desquamation on the face were moist, but this may have been due either to the moisture from the mouth or a secondary infection. The rapidity of spread of the lesion was perhaps its most outstanding feature. One of us (D.B.) has seen previously two examples of this disease, and on both occasions the spread of the desquamative process was so rapid as to flay large areas of the infant's body in the course of a few hours. In one of these cases the mother, on undressing the child, was as surprised and alarmed as was the mother in this case. These previous cases, seen before sulphonamide drugs were available, were fatal.

The course of treatment was based on the assumption that the infection was coccal. In the past only local treatment to the skin has been available, and such antiseptics as silver nitrate and potassium permanganate have been used, but with discouraging results. In this case the question naturally arose as to whether sulphapyridine should be applied to the skin, but in view of the almost complete absence of exudate from the exposed corium and the difficulty of applying sulphapyridine paste satisfactorily to a skin so liable to further exfoliation, it was decided that some penetrating antiseptic, namely gentian violet, should be applied over the child's whole body. With the further rise in temperature on the fourth and fifth day of the disease and in view of the repeated pure cultures of staphylococcus it was thought, mistakenly, that sulphathiazole might be a more efficient bactericidal agent; but it soon became obvious that the infant was in fact suffering from a mild degree of heat-stroke due to the thoroughness with which the local treatment had been carried out, 
and this view of the situation was confirmed by the rapid improvement in the child's condition when the painting of the skin was discontinued and a cooler cradle provided.

The repeated pure cultures of staphylococcus obtained from areas of corium which had recently been painted with gentian violet strongly suggest that such local treatment played little or no part in the recovery of this case. The failure of this application to destroy the staphylococcus in this case seems to contrast strikingly with general dermatological experience of the usefulness of this dye in cases of pemphigus neonatorum or bullous impetigo.

A search of the literature discloses only one case of this disease successfully treated with one of the sulphonamide group of drugs.

De Sanctis and De Lorenzo in 1941 reported the case of a sixteen days old infant who, shortly after the operation of circumcision on the seventh day of life, developed purulent vesicles and bullae about the mouth and upper extremities. This was followed by extensive exfoliation without further bullae formation, and cultures of the skin grew staphylococci and streptococci. The infant was treated with sulphathiazole and recovered.

Ryan and Goldman in 1940 reported four cases treated with sulphapyridine. They gave $0.39 \mathrm{gm}$. as an initial dose, followed by $0.13 \mathrm{gm}$. four hourly, for the first three days and 0.06 gm., six-hourly, subsequently. These doses are certainly small, and this may account for the hundred per cent. mortality which they record. All these infants had blood transfusions.

Scott (1941) described a fatal case of Ritter's disease in a negro infant in which the skin lesions were treated with a 1 per cent. aqueous solution of gentian violet, but he specifically mentions that the case came under his care before sulphapyridine and sulphathiazole were released for general clinical use, and the child did not recover.

There are a number of other cases of exfoliative dermatitis of the newborn recorded in the literature in which the skin lesion appears to be part of a more general infection.

Thus, Guy and Cohen (1929) described a fatal case in which bacillus pyocyaneus was isolated in pure culture from the heart blood at autopsy, and in this case there was a haemorrhagic cyst of the suprarenal and ulceration of the intestine. The condition appears to have been a septicaemia of the newborn with associated skin lesions.

Cairns (1923) described under the heading 'A Case of Ritter's Disease' the spread of a bullous lesion resembling pemphigus foliaceus starting on the seventh day of the infant's life and terminating fatally after eleven days. Even as late as the tenth day of the disease fresh bullae formed and, if it is correct to regard Ritter's disease as a clinical entity consisting entirely of rapid exfoliation of the epidermis without the formation of bullae, then, this case could more properly be classed as one of severe pemphigus.

It is, of course, impossible to conclude from this solitary case that sulphapyridine was the curative agent, but the entirely satisfactory outcome encourages the use of the drug when this rare condition is encountered. As has been indicated above it may well be that the widespread application of gentian violet is not only unnecessary but useless, and the danger of interfering with heat-loss by the adoption of such a technique must be borne in mind. 


\section{A CASE OF EXFOLIATIVE DERMATITIS OF THE NEWBORN 161}

No comment can be usefully made on the possible connexion between the mother's breast-infection and the infant's skin condition as no bacteriological record in the mother's case is available.

A tribute must be paid to the unremitting skill and care of the sister and nursing staff of the children`s department of Queen Mary's Hospital for the East End.

\section{REFERENCES}

Behrend, G. (1879). Vjschr. Dermat. Syph., 6, 191.

Cairns, R. (1923). Brit. med. J., 1, 186.

De Sanctis, A. G., and De Lorenzo, F. C. (1941). N.Y. St. J. Med., 41, 1361.

Guy, W. H., and Cohen, M. (1929). Arch. Derm. Syph., Chicago, 19, 425.

Leiner, C. (1930). In Jadassohn J., Handbuch der Haut -und Geschlechts-Krankheiten, Berlin, 14 , pt. 1.

Ritter von Rittershain, G. (1878-79). Zent. Ztg. Kinderheilk., 2, 3.

(1880). Arch. Kinderheilk., 1, 53.

Ryan, N. W., and Goldman, L. (1940). Amer. J. Dis. Child., 59, 1057.

Scott, R. B. (1941). Arch. Pediat., 58, 137. 